\title{
Food and Water Security in the Arab World and Sudan: Status and Threats
}

\author{
Nagat Ahmed Mus tafa Elmulthum ${ }^{1, *}$, Lubna Mohamed Mus a', Hanan Os manAli \\ ${ }^{1}$ Department of Agricultural Economics, University of Gezira, Sudan \\ ${ }^{2}$ Department of Soil Sciences, University of Gezira, Sudan
}

\begin{abstract}
Emphasizing the importance of food and water security, this study aimed at studying and analysing food and water security situation in the Arab World with special emphas is on Sudan. The Study employed descriptive statistics using secondary data collected from various sources. Results obtained indicated that food consumption gap in the Arab World increased by $24 \%$ in 2010 co mpared to 1973 . Results obtained indicated that the per capita available water in the Arab World decreased from $3430 \mathrm{~m}^{3}$ in 1960 to $1250 \mathrm{~m}^{3}$ in 2000 to $876 \mathrm{~m}^{3}$ in 2010 . A further decline in per capita available water to $667 \mathrm{~m}^{3}$ in 2025 and $500 \mathrm{~m}^{3}$ in 2050 is expected. These figures reflects a threatening situation for water and food security in the Arab World during the current century bearing in mind that the water poverty line is estimated at $1000 \mathrm{~m}^{3}$. The separation of Sudan into two countries has adversely affected the per capita available water in the democratic republic of Sudan. Results of the study proved that the self-sufficiency ratio of cereals in Sudan was less than $100 \%$ for most of the seasons during the period 1986/87-2006/07 indicating that production of cereal crops is below the consumption requirements of Sudanese people. The shift in consumption habits towards wheat in Sudan coupled with low comparative advantage resulted in low wheat self-sufficiency ratio during the period 1986/87-2007/08. Th is low self-sufficiency ratio in wheat gives an indication that the shortage in available food is mainly attributed to the significant consumption gap in wheat. Results indicated that wheat imports are real burden on Sudanese economy absorbing most of the foreign exchange generated from exports of Agricultural sector. Results obtained indicated that water productivity of Sorghum, Wheat and Groundnut grown in Gezira scheme in Sudan was very low compared to the average international water productivity. Based on the results of the study we recommend the allocation ofsubstantial financial resources to enhance food production, investment in water projects and efficient use of water with special consideration of health threats associated with the implementation of water projects. Development of along-termwater and food production plan for the Arab countries based on the principles of cooperation and equitable distribution is highly recommended.
\end{abstract}

Keywords Climate Change, Health Risks, Water Poverty line

\section{Introduction}

Food security is defined by[1] as access by all people at all times to enough food for an active and healthy life. Water resources sustainability is one of the important factors for food availability. A iming at raising the a wareness of people for the importance of water as a valuable resource United Nations has declared $2^{\text {nd }}$ of March as World Water day. According to[2] water security involves the sustainable use and protection of water systems, the protection against water related hazards (floods and droughts), the sustainable development of water resources and access to water services for humans and the environment.

Water is considered as a scarce resource with limited and fixed quantity. Water constitutes $70 \%$ of earth area which is

* Corresponding author:

nagathamt@gmail.com (Nagat Ahmed Mustafa Elmulthum)

Published online at http://journal.sapub.org/re

Copyright (C) 2012 Scientific \& Academic Publishing. All Rights Reserved equal to around $1400 \mathrm{~m} \mathrm{~km}^{3}$. Out of this quantity $97.5 \%$ is salt water from oceans and seas. The remaining $2.5 \%$ (35 m $\mathrm{km}^{3}$ ) is fresh water from which less than $1 \%$ is available for human use. This is because most of the fresh water is frozen in north and south poles or found as underground deep water unavailable for human use.

Water Resources are facing many challenges, important among which are the following -World population which is increasing at more than $2 \%$ annually is competing for the same amount of water from the beginning of live on earth. This,implies a continuous decrease in the per capita water available for use. An example for this threatening situation as indicated in [3] is that the average annual per capita available water in the middle east is expected to drop fro $1000 \mathrm{~m}^{3}$ in (2010) to $500 \mathrm{~m}^{3}$ in (2050) which is the least when it is compared to other regions in the world.

- According to (4) Arab countries face a serious food security challenge and that poverty rates are much higher than official numbers suggest. It blames the situationon vulnerability to volatile food prices, natural disasters and 
water scarcity

According to[5] climate change has resulted in some of atmospheric phenomena including increases in temperature, drought and flooding. These phenomena has resulted in water pollution, desertification and flooding with their negative impacts on food and water security. For one degree increase in temperature evaporation is expected to increase by $4 \%$

Most of water resources are shared by two or more countries. No international agreements are set for organizing the use of water of the shared sources. Water resources in the Arab region which are shared with other regions constitute $66 \%$ of all water available in the Arab world. This has (as reported in[6]) resulted in conflicts between some countries sharing water resources.

The Arab region is generally considered among the regions experiencing a severe shortage of water resources. It is argued by[7] that at least about $\$ 40$ billion of investments will be needed over the next ten years to meet the acute shortage of water, particularly in the supply of fresh water, which has become one of the main problems facing Arab development in general, and the tourism and agricultural sectors in particular. Thus, Arab States must spend $1 \%$ of their annual GDP to ensure adequate water resources, particularly in the major cities, because the Arab region is poor in water resources compared with the international average.

The number of Arab countries below the water poverty line increased from 3 countries in the middle of last century including Bahrain, Jordan and Kuwait to 11 in 1990 including Algeria Palestine, Qatar, Saudi Arabia, Somalia, Tunisia, United Arab Emirates, and Yemen. Seven more countries are expected to be below the water poverty line by 2025, (as in[6]).

The importance, of resolving the issues of increasing water scarcity and climate change in the Arab region through innovation, science, investments and integrated water management and technological solutions was underlined by[8]. It also reiterated the need to strengthen knowledge, exchange information and recognize the fundamental role of water and food security in ensuring a stable political and economic future for an Arab region that is currently going through dramatic social and political transition.

According to[9] the enlargement of Roseires Dam in Sudan by raising the height of Dam wall by $10 \mathrm{~m}$ will result in some benefits e.g. increasing energy output by $500 \mathrm{GWH}$ per year, allow for the development of new irrigation schemes in the future that would boost the economy of the country, improved health facilities for resettlement communities and provide essential services. However, the enlargement of Roseires Dam is expected to introduce important ecological and social changes in the environment that will produce a number of health risks which requires mitigation measures.

The need of food crops for water differs by the type and stage of growth of crops. In addition, water is considered as the source of live for aquatic animals. Moreover, water is very crucial for natural range lands which depend on rainfall, whilepasturesdepend on irrigation and permanent creeks flow(as in [5]). It is reported in[10] that agriculture in Sudan accounts for the lion's share in the economic and social activities, contributing more than $40 \%$ of GDP in 1960 s through 1980s, which declined to $36 \%$ in 2008. Three key policy recommendations emerge from (4) include improvement of data and capacity as the basis for evidence-based decision making. In addition, fostering growth that enhances food security at national and hous ehold levels is highly recommended. Moreover, enhancing the efficiency and retooling the allocation of public spending is expected to have a positive impact on food security in the Arab World.

According to[11] Sudan was food insecure during the period 1986/1987-2007/08. The forecasted levels of self-sufficiency ratio in cereals during the period 2008/09-2019-2020 suggested that this situation is expected to continue during the next decade with the gap in wheat significantly contributing to the problem. According to[12] a ten per cent drop in annual rainfall results in 5.0, 7.3, and 3.0 percent in the production of total cereals, sorghum and millet in Sudan, a result which confirms the negative impact of climate change on Food Security in Sudan. Results obtained by[13] gave signs of negative impacts of trade liberalization and domestic polices on food security situation in Sudan. In addition, high levels of poverty negatively affect the ability of people to access the recommended amounts of food. This paper, aimed at studying and analysing food and water security situation in the Arab World in general and in Sudan in particular.

\section{Methodology}

The study was based onsecondary datacollected from various sources. Data collected includedvariables related tofood andwater securityin the Arab World in general andSudanin particular.Researchers employed descriptive statistics for analysis. Data from[6] was employed to analyse results related to self-sufficiency ratio in food of some of food items common in people diets in the Arab World and for food consumption gaps in the Arab World during the period 1973-2010. Aiming at reflecting water availability in the Arab world the authors used data on per capita available water in the Arab Worldfrom[3]. Based on data from[14] the food security situation in Sudan during the period 1986/87-2006/07 was analysed.

\section{Results and discussion}

Agriculture is the highest userof the world'sfresh water. It is estimated that $70 \%$ of the totalwater resourcesderived from lakes,waterwaysand aquifers is consumed by their rigation sector. The average requirement ofdrinking waterper personper day is estimated at 3 litres. The average daily amount of water required for producing daily per capita food 
consumption requirement is estimated at 3500 litres. Agricultureuses 10001itres of water to produceonekgof grain. This amount is higher in Africa and Asia because of mis management of water use. Water requirement for production of one $\mathrm{kg}$ of rice is estimated at 1000-3000 litres of water. One $\mathrm{Kg}$ of beef fed by grains requires 13000150001 itres of water (as in[3]).

Scarcity of water may cause up to $10 \%$ food shortage which will be reflected in higher food prices affecting 103 million people earning one dollarorless per day. Water security is highly crucial for sustainable food supply accessible by everybody. Results in figure (1) indicated that self-sufficiency ratio in food in the Arab World for the year 2010 depends on the type and elasticity of food items. It is low for cereals and high for vegetables and fruits.

Results obtained indicated that food consumption gap in the Arab world increased from $\$ 1.1$ billionsin 1973 to $\$ 27$ billions in 2010 (24\%) (figure 2). This may be attributed to a number of factors including population growth, reduction of real income, and the impact of climate change which negatively affected per capita available water and agricultural production. Results obtained indicated that the per capita availab le water in the Arab World decreased from $3430 \mathrm{~m}^{3}$ in 1960 to $1250 \mathrm{~m}^{3}$ in 2000 to $876 \mathrm{~m}^{3}$ in 2010 . A further decline in per capita availab le water to $667 \mathrm{~m}^{3}$ in 2025 and $500 \mathrm{~m}^{3}$ in 2050 is expected (figure 3 ). These figures reflects a threatening situation for water and food security in the Arab World during the current century bearing in mind that the water poverty line is estimated at $1000 \mathrm{~m}^{3}$. According to[15] the separation of Sudan into two countries has resulted in a decline in per capita available water for democratic republic of Sudan from $787.5 \mathrm{~m}^{3}$ to $555.5 \mathrm{~m}^{3}$.

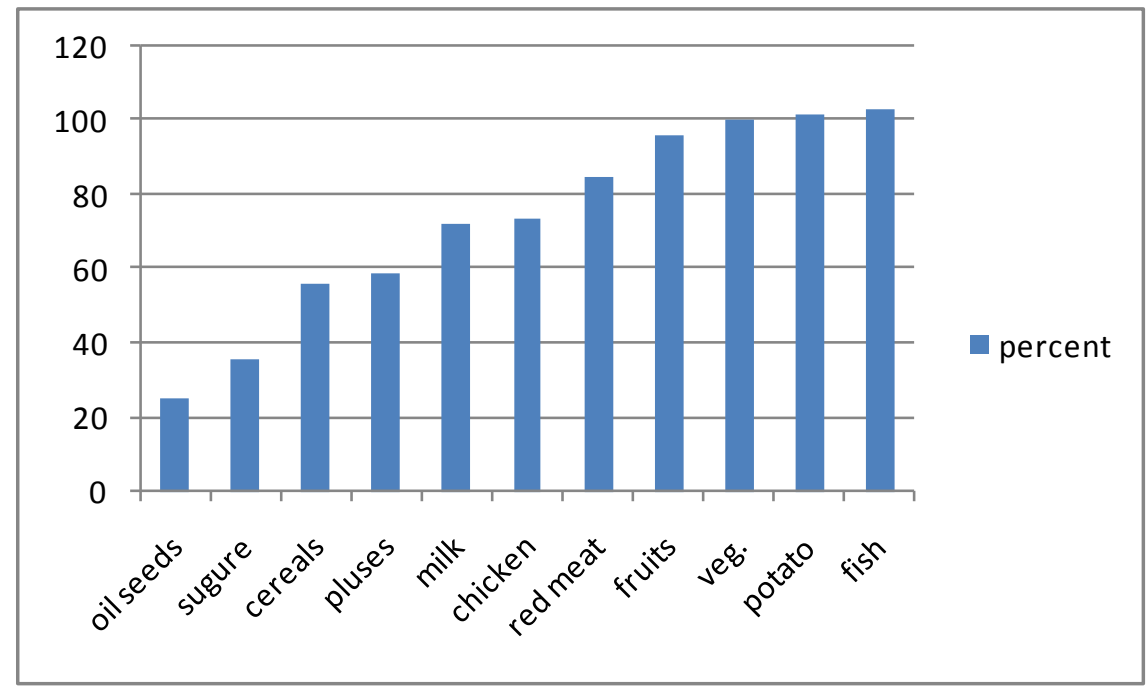

Figure (1). Self-sufficiency in food in the Arab World (2010). Source: Authors' presentation based on [6]

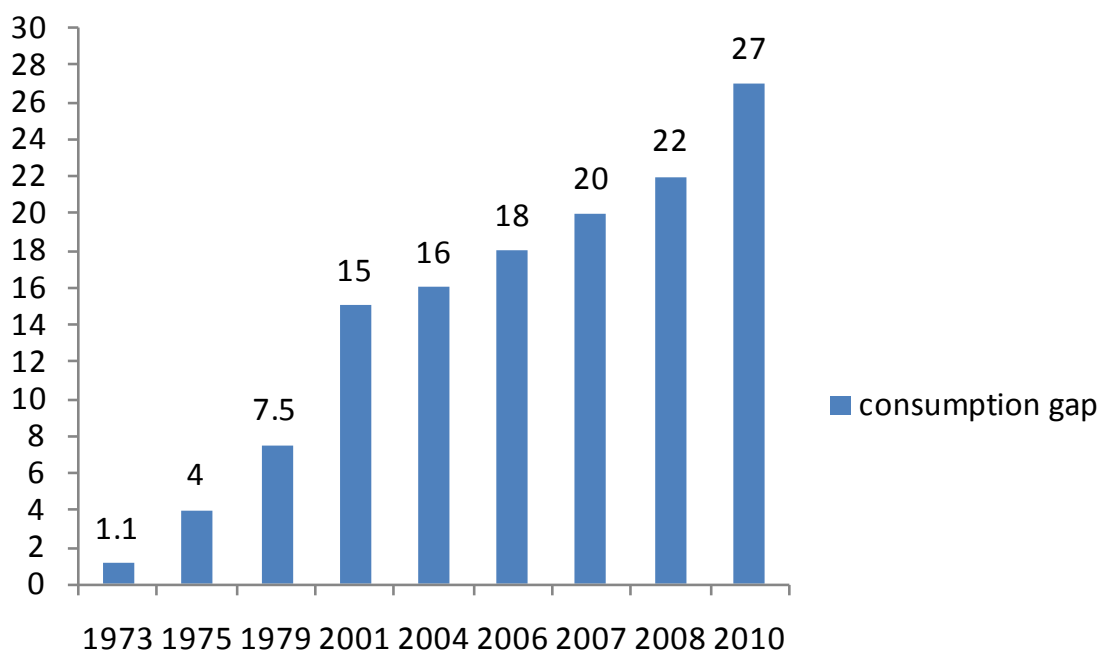

Figure (2). Food consumption gap in the Arab World ( \$ billions ) 1973-2010. Source: Authors' presentation based on[6] 


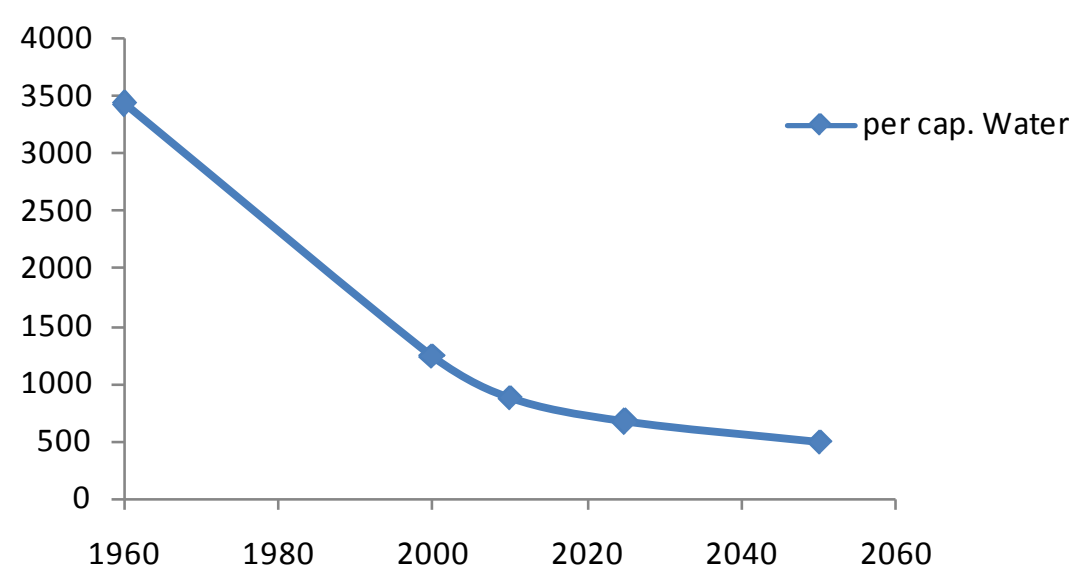

Figure (3). Per capita available water in the Arab World in $\mathrm{m}^{3}$. Source: Authors' presentation based on[3]

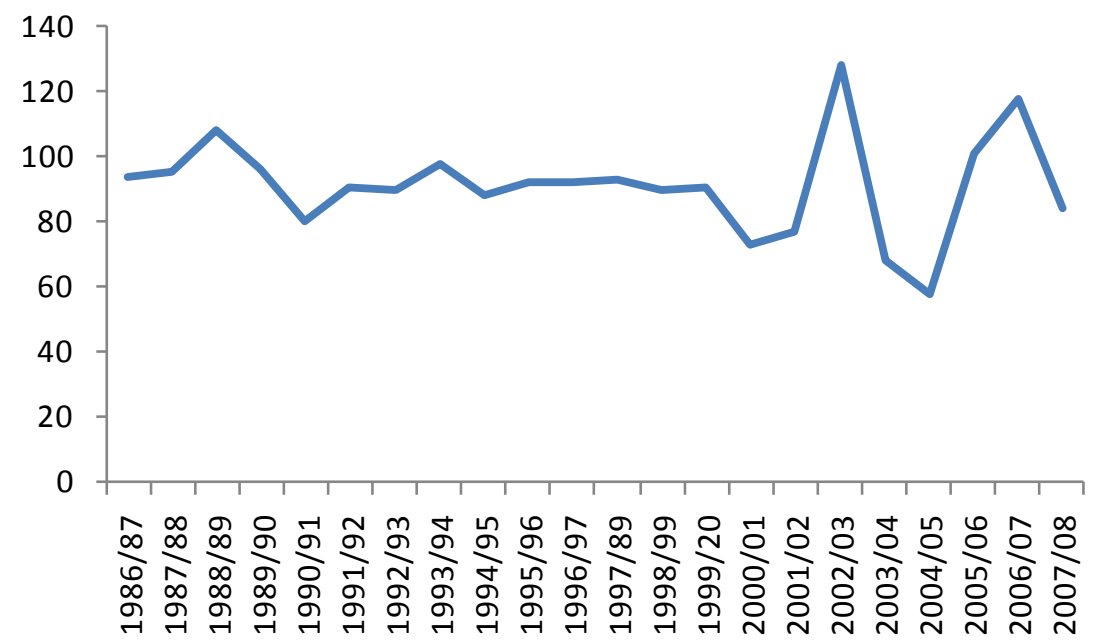

Figure (4). Self-sufficiency Ratio in Cereals in Sudan (1986/87-2006/07). Source: Authors' presentation based on[14]

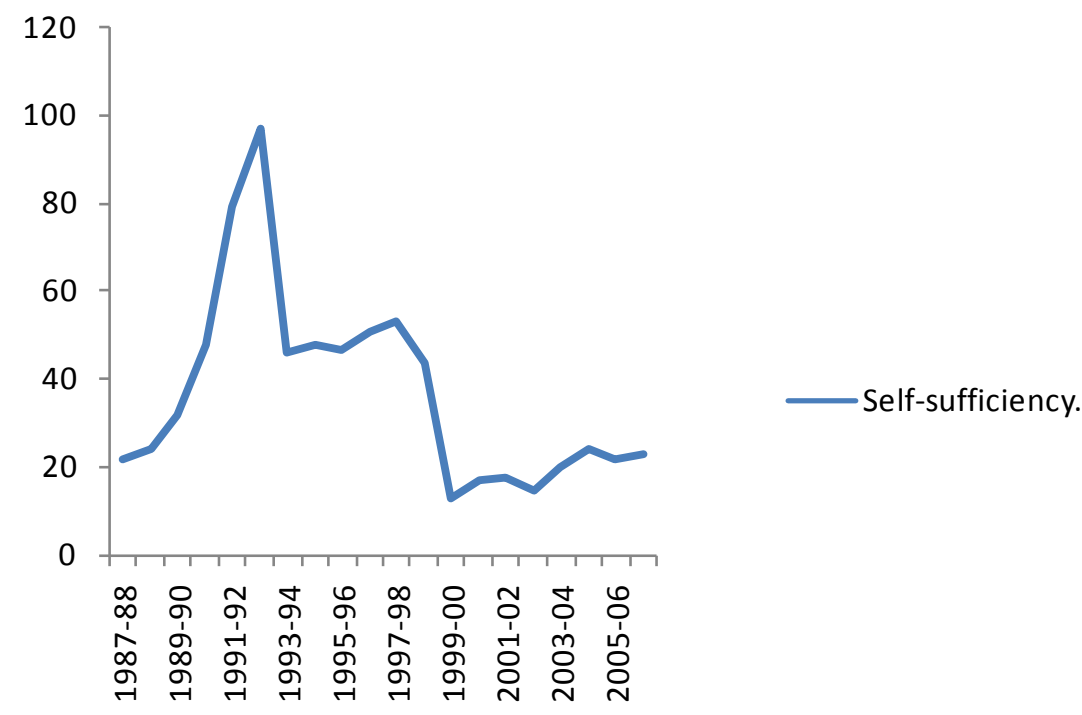

Figure (5). Self-sufficiency Ratio in Wheat in Sudan(\%).Source: Authors' presentation based on[14] 


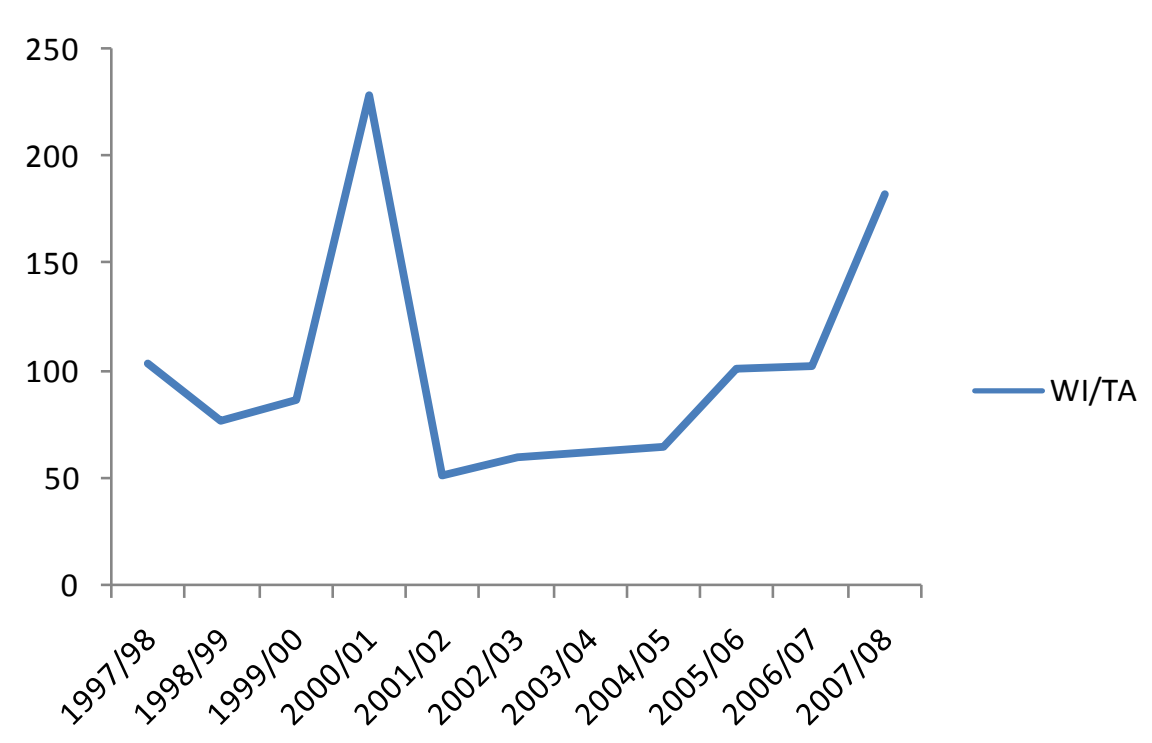

Figure (6).Percentage of Wheat imports (WI)/Total Agric. Exports (T A). Source: Authors' presentation based on[14]

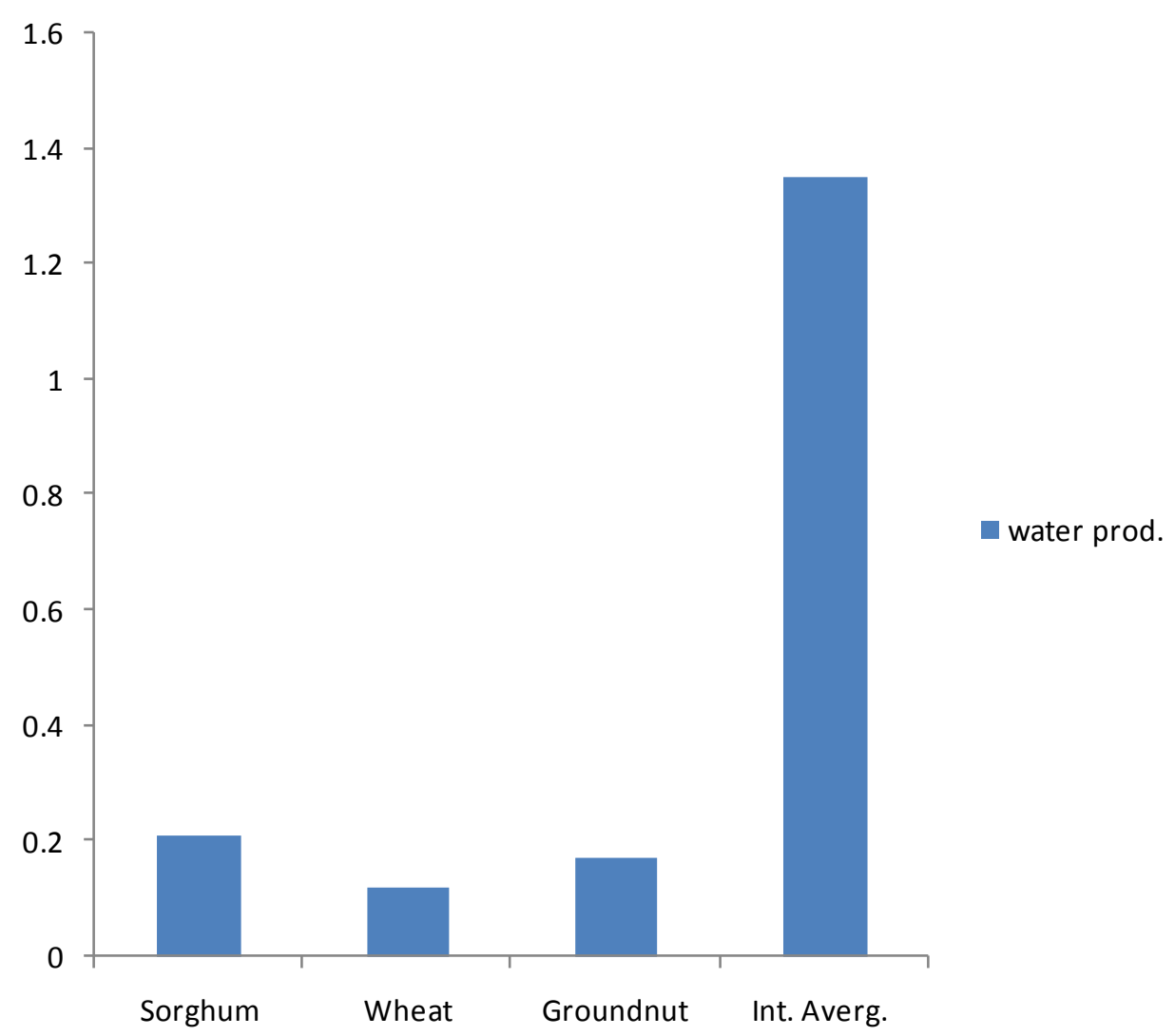

Figure (7). Water productivity kg/m ${ }^{3}$ in Gezira Scheme, Sudan. Source: Authors' presentation based on[16]

It is clear from figure (4) that, with the exception of the $1988 / 1989-2002 / 03,2005 / 06,2006 / 07$ seasons, the self-sufficiency ratio in cereals in Sudan was less than $100 \%$ indicating that production of cereal crops is below the consumption requirements of Sudanese people during the period 1986/1987-2007/08. The degree of food insecurity measured by the self-sufficiency ratio differs from one year to another depending on the food consumption gaps.

Results in (figure 5)indicated that the shift in consumption habits towards wheat coupled with low comparative advantage of growing wheat in Sudan resulted in low self-sufficiency ratio during the period 1986/87-2007/08. 
This low self-sufficiency ratio of wheat gives an indication that the shortage in available food in Sudan is mainly attributed to the significant consumption gap in wheat. Results in figure (6) indicated that wheat imports (WI) are real burden on the economy absorbing most of the foreign exchange generated from total exports of Agricultural sector (TA).

Applying data from[16] results obtained indicated that water productivity of food crops is very low in Sudan. Figure (7) shows that average water productivity of Sorghum, Wheat and Groundnut was estimated at $0.21 \mathrm{~kg} / \mathrm{m}^{3}$, $0.12 \mathrm{~kg} / \mathrm{m}^{3}$ and $0.17 \mathrm{~kg} / \mathrm{m}^{3}$, respectively. These figures are very low compared to the average international water productivity of these crops which was estimated at 1.35 $\mathrm{kg} / \mathrm{m}^{3}$.

\section{Conclusions and Recommendations}

Analys is of the current situation of food and water security reflects a threatening situation in Sudan and the Arab World during the current century. Based on the results of the study we recommend the allocation ofsubstantial financial resourcesto enhancefood productionby investing inagricultural technology, education, health, nutrition, agricultural extension,and infrastructure. In addition, investment in water projects(damsand agricultural projects) in order toachieve food security is of highly importance with special consideration of health threats associated with the implementation of water projects. Moreover, emphasis should be placed on increasing the efficiency of water use through raising the awareness of citizens and decision makers of the efficient use of water. Furthermore, we recommend the development of along-termwater and food production plan between the Arab countriesbased on theprinciple of cooperation and the principle ofequitable sharing.

\section{REFERENCES}

[1] World Bank. Poverty and Hunger: Issues and Options for Food Security in the Developing Countries, Washington DC.,1986.

[2] Schultz, B. and S. Uhlenbrook "Water Security What Does it Mean, What may it Imply". Discussion Paper UNISCO-IHE, 2007.
[3] Shalabi, M. "Water Security in the Arab World: Continuous Threats and Repeated Recommendations" www. nodhoob. com/ind ex.php/water/475-59.2000

[4] IFPRI "Beyond the Awaking: Polices and Investment for poverty Reduction and Food Security. www, ifpri. org/publication/2012

[5] Eltahir, F. "Water and Food Security". Ministry of Agriculture, IPC, Sudan (in Arabic).2011.

[6] Allozy, S. Food Consumption Gap and Food Security in the Arab World. www.aoad.org/drlozy.doc. (in Arabic).2010.

[7] Sawaha,A.Arab Water Security and Related Challengeshttp:/ /www.memrieconomicblog.org/bin/content.cgi?article=123 , 2008.

[8] IFADhttp://www.emwis.net/thematicdirs/news/2012/02/ifadsupp orts-efforts-develop-arab-water-security-strategy, 2011 .

[9] Amin, M. and A. Mahmoud "Health Impact Assessment of the Heightening of Roseires Dam". presented at conference of Food Security and Poverty alleviation under changing enviromental conditions: Challenges and Opportunities in Sudan, Khartoum, Sudan.2011.

[10] Ahmed,M.M.. Global financial crisis, discussion paper Series 19, Sudan Phase2 www.odi.org.uk/resources/download2010.

[11] Elmulthum, N.A., M.A., Awaad, and A. E. Elamin,.:Can Sudan achieve food security during the next decade?: some forecasts of self-sufficiency in cereals Scientific Research and Essays Vol. 6(3), pp. 529-532, Academic Journals.2011

[12] Elhag, M., M.H. Suliman, and N. A. Elmulthum. Can Sudan Achieve Food Security Under Climate Change and Violence? 10th international conference of African Crop Science Society Maputo Mozambique, 9th-13 ${ }^{\text {th }}$ October 2011 Conference.

[13] Elmulthum, N.A..,and E.E.I.Abdalkrim The Impact of World prices and domestic policies on food security in the Sudan. Gezira Journal of Agricultural Sciences: 6 (2):207-228.2008.

[14] Elmulthum, N.A andM. AAbdelmawla" Availability and Accessibility to Food as Pillars of Food Security in Sudan" presented at conference Food Security and Poverty alleviation under changing environmental conditions: Challenges and Opportunities in Sudan, Khartoum, Sudan.2011.

[15] Sudan, Ministry of information Sudan the Land of Opportunities. www.profile.gov.sd/ar/index.php (in Arabic). 2007.

[16] Osman, A. Land and Water Productivity of the Main Crops in Gezira Scheme (1978-2007). M.Sc. Thesis, Water Management and Irrigation Institute, University of Gezira, Sudan.2009. 